\title{
TRADIÇÃO E MODERNIDADE NA POESIA DE AUGUSTO MEYER
}

Bruno Brizotto $^{*}$ e Lisana Teresinha Bertussi ${ }^{\dagger}$

Resumo: As relações entre os conceitos de tradição e modernidade constituem uma das formas de compreender a poesia de Augusto Meyer. Nessa perspectiva, este artigo analisa como os referidos conceitos constroem a poesia desse autor, à luz de poemas selecionados.

Palavras-chave: Augusto Meyer, Tradição, Modernidade, Poesia regionalista modernista gauchesca.

Abstract: The relationship between the concepts of tradition and modernity is one of the ways to understand the poetry of Augusto Meyer. In this perspective, this article examines how these concepts build the poetry of this author, in the light of selected poems.

Keywords: Augusto Meyer, Tradition, Modernity, Gaucho regionalist modernist poetry.

* Mestrando do Programa de Pós-Graduação em Letras, Cultura e Regionalidade da Universidade de Caxias do Sul. Bolsista da CAPES. E-mail: brunobrizotto@terra.com.br.

† Doutora em Teoria da Literatura pela Pontifícia Universidade Católica do Rio Grande do Sul. Docente e pesquisadora da Universidade de Caxias do Sul. E-mail: zanabertussi@terra.com.br. 


\section{TRADIÇÃO E MODERNIDADE NA POESIA DE AUGUSTO MEYER}

Bruno Brizotto e Lisana Teresinha Bertussi

Ao examinar a produção poética dos principais representantes da poesia regionalista gauchesca ${ }^{1}$ de 1922 a 1932, isto é, aqueles que integraram a primeira fase do Modernismo gaúcho (Augusto Meyer, Manuel do Nascimento Vargas Netto, Tyrteu Rocha Vianna, João Otávio Nogueira Leiria), percebemos que a poética de cada um articula os conceitos de tradição e modernidade, dando nova configuração ao regionalismo sul-rio-grandense, na medida em que o integra ao Modernismo nacional. Essa reconfiguração, conforme assevera Schüler (1987, p. 143), apresenta "a poesia [enveredando-se] por novos rumos sem romper com a tradição." Portanto, os poetas dessa geração "entraram em processo de renovação sem esquecer o legado local.” (SCHÜLER, 1987, p. 144).

Diante desse panorama, este estudo concentra-se na forma como o poeta porto-alegrense Augusto Meyer (1902-1970) renova o

\footnotetext{
${ }^{1}$ Deve-se a Guilhermino Cesar a denominação poesia regionalista gauchesca, feita na sua História da Literatura do Rio Grande do Sul (1956).
} 
regionalismo gaúcho, através do Simbolismo e do Modernismo, estabelecendo um diálogo ímpar entre tradição e modernidade na poesia regionalista gauchesca. Colocam-se, então, as seguintes questões: como configurar os conceitos de tradição e modernidade? $\mathrm{E}$ como fazê-lo, levando em conta o percurso histórico da gauchesca em suas diferentes fases: literatura oral, Romantismo e Modernismo?

\section{Configurando os conceitos de tradição e modernidade}

De acordo com Lawn (2011, p. 193), "a palavra tradição vem do latim traditio, derivada do verbo tradere, que significa literalmente ceder ou dar alguma coisa. Portanto, a tradição é literalmente aquilo que é cedido ou dado - ou o processo de ceder ou passar -, de geração a geração.” Elemento importante para a edificação da hermenêutica filosófica de Hans-Georg Gadamer (1900-2002), a tradição ganha "nova cidadania" no projeto gadameriano. Tal projeto efetiva-se na obra Verdade e método: traços fundamentais de uma hermenêutica filosófica, sendo publicada originalmente em alemão com o título Wahrheit und Methode, em 1960. O objetivo de Gadamer é mostrar que a verdade pode ser atingida por meio de outras formas, e não somente pelo uso do método, como queria a filosofia moderna de Descartes. A estrutura da obra explicita o intento de seu autor, apresentando três experiências básicas da verdade: a arte, a compreensão histórica e a 
linguagem. ${ }^{2}$ É na segunda parte que Gadamer (2008, pp. 361-378) reabilita três conceitos fundamentais para a hermenêutica, os quais sofreram descrédito no Iluminismo, a saber: preconceito, autoridade e tradição. A tradição, enquanto forma de autoridade, é caracterizada pelo autor da seguinte maneira:

O que é consagrado pela tradição e pela herança histórica possui uma autoridade que se tornou anônima, e nosso ser histórico e finito está determinado pelo fato de que também a autoridade do que foi transmitido, e não somente o que possui fundamentos evidentes, tem poder sobre nossa ação e nosso comportamento. [...] A realidade dos costumes, p. ex., é e continua sendo, em sentido amplo, algo válido a partir da herança histórica e da tradição. Os costumes são adotados livremente, mas não são criados nem fundados em sua validade por um livre discernimento. É isso, precisamente, que denominamos tradição: ter validade sem precisar de fundamentação. [...] A tradição é essencialmente conservação e como tal sempre está atuante nas mudanças históricas. (GADAMER, 2008, pp. 372-373)

A caracterização do conceito de tradição operada por Gadamer (2008) vai ao encontro da essência da tradição da poesia regionalista gauchesca sul-rio-grandense. Primeiro: a tradição

\footnotetext{
${ }^{2}$ A parte 1 é intitulada: "A liberação da questão da verdade a partir da experiência da arte"; a parte 2: "A extensão da questão da verdade à compreensão nas ciências do espírito" e a parte 3: "A virada ontológica da hermenêutica no fio condutor da linguagem".
} 
"possui uma autoridade que se tornou anônima", tal como ocorre com a produção poética da literatura oral, que, posteriormente, foi compilada e publicada, graças a João Simões Lopes Neto, Augusto Meyer e Apolinário Porto Alegre. Segundo: o fato de "os costumes [serem] adotados livremente, mas não [serem] criados nem fundados em sua validade por um livre discernimento", levou a poesia regionalista romântica a fundamentar a figura do gaúcho em duas figuras mitológicas: o "monarca das coxilhas" e o "centauro dos pampas". E terceiro: já que a "tradição é essencialmente conservação e como tal sempre está atuante nas mudanças históricas", pode estabelecer diálogo com a modernidade, sem perdas para ambos os lados. Na esteira dessa questão, é apropriada a afirmação de Lawn (2011, p. 172): “A tradição de Gadamer não é o peso apavorante das gerações mortas, mas sim uma interação dialógica incessante entre o passado e o presente."

O poeta modernista e crítico literário inglês T. S. Eliot (18881965) também apresenta uma interessante interpretação para o conceito de tradição. Segundo o autor, a tradição

[...] supõe, em primeiro lugar, o sentido histórico, que podemos dizer praticamente indispensável a qualquer um que continue a ser poeta depois dos 25 anos de idade; e o sentido histórico supõe uma percepção, não apenas do que é passado do passado, como também daquilo que permanece dele; o sentido histórico leva um homem a escrever não só com sua própria geração entranhada até a medula, mas ainda com a sensação de que toda a literatura da Europa desde Homero, e 
dentro dela toda a literatura de seu país, possui uma existência simultânea e compõe uma ordem simultânea. O sentido histórico, que é um sentido tanto do intemporal quanto do temporal, e do intemporal e do temporal juntos, é o que torna um escritor tradicional. E é, ao mesmo tempo, o que torna um escritor profundamente consciente de seu lugar no tempo, de sua própria contemporaneidade. Nenhum poeta, nenhum artista de qualquer arte, tem seu pleno significado sozinho. (ELIOT, 1932, pp. 14-15) ${ }^{3}$

Fica claro que o posicionamento de Eliot (1932) diz respeito à atividade do poeta, do escritor. $\mathrm{O}$ fato de a tradição levar em conta o sentido histórico permite a ela articular-se com a modernidade, na medida em que o poeta está consciente "de seu lugar no tempo, de sua própria contemporaneidade." (ELIOT, 1932, p. 15). Mesmo poetas modernistas como Mário de Andrade, Manuel Bandeira, Walt

\footnotetext{
${ }^{3}$ No original: "[...] involves, in the first place, the historical sense, which we may call nearly indispensable to anyone who would continue to be a poet beyond his twenty-fifth year; and the historical sense involves a perception, not only of the pastness of the past, but of its presence; the historical sense compels a man to write not merely with his own generation in his bones, but with a feeling that the whole of the literature of Europe from Homer and within in the whole of the literature of his own country has a simultaneous existence and composes a simultaneous order. This historical sense, which is a sense of the timeless as well as of the temporal and of the timeless and of the temporal together, is what makes a writer traditional. And it is at the same time what makes a writer most acutely conscious of his place in time, of his own contemporaneity. No poet, no artist of any art, has his complete meaning alone."
} 
Whitman, Fernando Pessoa estão inseridos dentro de uma tradição, pois o poeta, o romancista, o contista não possui "seu pleno significado sozinho." (ELIOT, 1932, p. 15).

Seguindo a estratégia de configurar os conceitos-chave deste estudo, examinam-se os sentidos que o termo modernidade apresenta, ao levar em conta as análises efetuadas por Baudelaire (1996), Benjamin $(1975 ;$ 2002) e Berman (1986). Tanto Benjamin (1975; 2002) quanto Berman (1986) creditam posição de destaque para o poeta francês Charles Baudelaire (1821-1867), que, mesmo tendo vivido e produzido sua poesia na época do Romantismo e se aproximando dos parnasianos e realistas, já antecipa muitos dos traços da vida moderna. Ao lado de sua produção poética, Baudelaire (1996, p. 25) mostra-se um dos maiores críticos acerca da caracterização da modernidade: “A Modernidade é o transitório, o efêmero, o contingente, é a metade da arte, sendo a outra metade o eterno e o imutável." Essa conceituação de modernidade é, de acordo com Benjamin (1975, p. 17), "a melhor", pois relaciona antiguidade e modernidade: "A modernidade caracteriza uma época; caracteriza simultaneamente a força que age nesta época e que faz com que ela seja parecida com a antigüidade." (BENJAMIN, 1975, p. 17). O filósofo alemão também afirma que Baudelaire estava consciente de sua tarefa de "dar feição à modernidade" (BENJAMIN, 1975, p. 17), fato que corrobora o papel de destaque do poeta francês para a configuração da modernidade. Escreve Benjamin (1975, p. 17): “na época em que [Baudelaire] vivia, nada se aproxima tanto da 'tarefa' 
do herói antigo, dos 'trabalhos' de um Hércules, como a tarefa de que ele próprio se impôs: dar feição à modernidade." O diálogo entre passado e presente faz-se presente em outro argumento de Baudelaire (1996, p. 8):

O passado é interessante não somente pela beleza que dele souberam extrair os artistas para quem constituía o presente, mas igualmente como passado, por seu valor histórico. $\mathrm{O}$ mesmo ocorre com o presente. $\mathrm{O}$ prazer que obtemos com a representação do presente deve-se não apenas à beleza de que ele pode estar revestido, mas também à sua qualidade essencial de presente.

Mas quem seria o indivíduo capaz de dar forma à modernidade? Para Baudelaire (1996, p. 16), é o "homem do mundo" o artista capaz de poetizar seu tempo. Observe-se:

Quando finalmente o conheci [o Sr. G.], logo vi que não se tratava precisamente de um artista, mas antes de um homem do mundo. Entenda-se aqui, por favor, a palavra artista num sentido muito restrito, e a expressão homem do mundo num sentido muito amplo. Homem do mundo, isto é, homem do mundo inteiro, homem que compreende o mundo e as razões misteriosas e legítimas de todos os seus costumes; artista, isto é, especialista, homem subordinado à sua palheta como o servo à gleba. [grifos do autor]

Assim, é este "homem do mundo" quem colocará em prática o que Baudelaire acredita ser a arte moderna: a valorização da 
circunstância, a poetização das coisas aparentemente insignificantes, a paixão insaciável de ver e sentir a multidão, a curiosidade pela vida urbana do homem do mundo, o dandismo, a consideração pela moda e pela mulher, o uso da imaginação como ferramenta para configurar a memória do tempo.

Além de apontar a relevância de Baudelaire para a configuração da modernidade, Benjamin (2002) em seu texto clássico “Paris, capital do século XIX”, editado em 1935, dá a sua contribuição para a caracterização da modernidade, a tomar a cidade de Paris como exemplo de cidade que cresce e se urbaniza em extensão, como o referido texto descreve em detalhes. Para realizar tal intento, o autor divide o texto em seis seções: "Fourier ou as passagens", "Daguerre ou os panoramas", "Grandville ou as exposições universais", "Luís Felipe ou o interior", "Baudelaire ou as ruas de Paris" e "Haussmann ou as barricadas". As passagens, os panoramas, as exposições universais, o interior, as ruas e as barricadas, ao lado de figuras representativas (Fourier, o filósofo socialista criador do Falanstério; Daguerre, o pintor, cenógrafo, físico e inventor francês, que foi, em 1835, autor da primeira patente para um processo fotográfico, o daguerreótipo; Grandville, o caricaturista francês, cujas ilustrações foram utilizadas por Benjamin; Luís Felipe, o último rei da França de 1830 a 1848; Baudelaire, poeta e crítico da modernidade; Haussmann, prefeito de Paris, sendo nomeado por Napoleão III, dono do título de Barão e grande remodelador de Paris, cuidando do planejamento da cidade, durante 17 anos, com a 
colaboração de arquitetos e engenheiros renomados de Paris na época) criam um espaço que certamente coloca Walter Benjamin como um dos grandes arquitetos para a edificação do termo modernidade.

Ao lado de Baudelaire e Benjamin, Marshall Berman em Tudo que é sólido desmancha no ar: a aventura da modernidade, lançado em 1982, engendra um estimulante e rico estudo sobre o termo modernidade. O título da obra, apesar de partir de uma frase aparentemente banal do Manifesto Comunista de Marx e Engels Tudo que é sólido desmancha no ar -, serve de motivo para que Berman construa um painel da modernidade dos séculos XIX e XX. $O$ centro da investigação do autor se concentra nos modernistas do século XIX (Goethe, Marx, Nietzsche, Baudelaire, Dostoievski), pois é a partir deles, modernistas antes da escola, que poderemos compreender os modernistas do século XXI. Escreve Berman (1986, p. 35): "Apropriar-se das modernidades de ontem pode ser, ao mesmo tempo, uma crítica às modernidades de hoje e um ato de fé nas modernidades - e nos homens e mulheres modernos - de amanhã e do dia depois de amanhã." Fica claro que a modernidade do século XIX, vista com o olhar de hoje, constitui uma tradição da modernidade, como quer o seu autor: "a modernidade, no curso de cinco séculos, desenvolveu uma rica história e uma variedade de tradições próprias." (BERMAN, 1986, p. 15). A partir disso, deslindase a intenção de Berman (1986, p. 15): "explorar e mapear essas tradições, a fim de compreender de que modo elas podem nutrir e 
enriquecer nossa própria modernidade e como podem empobrecer ou obscurecer o nosso senso do que seja ou possa ser a modernidade."

Quando examina a contribuição de Baudelaire $^{4}$ para a constituição da modernidade, Berman (1986, p. 129) afirma sobre o poeta francês que ele "fez mais do que ninguém, no século XIX, para dotar seus contemporâneos de uma consciência de si mesmos enquanto modernos." Uma das qualidades mais evidentes dos muitos escritos de Baudelaire que Berman (1986) destaca reside justamente na conceituação surpreendentemente vaga, difícil de determinar que o poeta francês imprime à modernidade. Para o filósofo norteamericano essa conceituação é altamente útil, na medida em que serve "romper com as antiquadas fixações clássicas que dominam a cultura francesa." (BERMAN, 1986, p. 130). Contudo, Berman (1986, p. 131) destaca que o percurso da obra de Baudelaire apresenta "várias visões distintas da modernidade." E arremata:

Essas visões muitas vezes parecem opor-se violentamente umas às outras, e Baudelaire nem sempre parece estar ciente das tensões entre elas. Mais do que isso, ele sempre as apresenta com verve e brilho e quase sempre as elabora com grande originalidade e profundidade. Mais ainda: todas as modernas visões de Baudelaire e todas as suas contraditórias atitudes críticas em relação à modernidade adquiriram vida

${ }^{4}$ Cf. o capítulo III, intitulado "Baudelaire: O Modernismo nas Ruas" (p. 127-165), para maiores detalhes sobre a análise de Berman em relação à Baudelaire. 
própria e perduraram por longo tempo após sua morte, até o nosso próprio tempo. (BERMAN, 1986, p. 131)

Apesar das "visões distintas da modernidade" professadas por Baudelaire, o que fica como elemento-chave é o fato de que ele configurou a modernidade como nenhum outro o fez, salvo Benjamin e Marx, e que essa configuração permite que se faça, hoje, toda uma reflexão sobre os verdadeiros sentidos que o termo modernidade pode apresentar, tarefa realizada com muita perspicácia por Berman (1986).

\section{Augusto Meyer: inserção no Modernismo gaúcho e perfil poético}

Augusto Meyer (1902-1970) foi poeta, cronista, ensaísta, jornalista, memorialista e folclorista, atividades que o fazem um dos maiores nomes da literatura gaúcha do século XX. Dentre suas várias realizações, pode-se citar: professor de Literatura na Faculdade de Direito de Porto Alegre, diretor da Biblioteca Pública do Estado do Rio Grande do Sul (1930 a 1936), diretor do INL (no RJ, de 1938 a 1956), Diretor de Curso sobre Estudos Brasileiros na Alemanha (1955), professor de Teoria da Literatura na Faculdade de Filosofia do RJ, Membro do Conselho Federal de Cultura (desde 1967). Foi membro da Academia Brasileira de Letras (eleito em 12 de maio de 1960) e da Academia Brasileira de Filologia. Em 1947, recebeu o Prêmio Filipe de Oliveira na categoria Memórias e, em 1950, o Prêmio Machado de Assis da Academia Brasileira de Letras pelo 
conjunto de sua obra literária. Como poeta, publicou: Ilusão querida (1923); Coração verde (1926;); Giraluz (1928); Duas orações (1928); Poemas de Bilu (1929); Sorriso interior (1930); Literatura e poesia poemas em prosa (1931) e Poesias - 1922-1955 (1957). Juntamente com Raul Bopp e Mário Quintana, Meyer completa a trindade modernista do Rio Grande do Sul.

A delimitação do início do Modernismo no Rio Grande do Sul apresenta discussões e disparidades ${ }^{5}$, mas é fato incontestável que Ilusão querida, Coração verde e Giraluz estão entre as obras fundadoras do movimento modernista no estado. Segundo Carvalhal $(1987,12)$, "a poesia de Meyer integrava a produção dos 'novos do Sul.” Essa denominação, que abarca nomes como Theodemiro Tostes, Ruy Cirne Lima, Vargas Netto, Athos Damasceno Ferreira, Raul Bopp, se deve ao fato de cada um deles ter acolhido "em medidas diferentes e cada um a seu modo o ideário modernista de 22." (CARVALHAL, 1987, p. 12). No que diz respeito aos críticos gaúchos, estes apontaram com contundência o papel de Meyer para o desenvolvimento do Modernismo em terras gaúchas: Moysés Vellinho (1960, p. 35) afirma que Meyer foi o poeta que "tirou maior partido do movimento"; Regina Zilberman (1982) destaca sobre Meyer: "um dos principais mentores do Modernismo no Rio Grande do Sul." (p. 52). E em seguida afirma: "Meyer teve papel capital no desenvolvimento do processo poético no âmbito sulino, pelos frutos que gerou." (p. 55); para Luís Augusto Fischer (2004, p. 78), Meyer

\footnotetext{
${ }^{5}$ Para a discussão desta questão, ver CESAR (1971) e SCHÜLER (1987).
} 
consiste na "figura central do movimento sulino."; Donaldo Schüler (1987) completa: "Augusto Meyer mostra-se poeta globalizador. Todas as tendências confluem nele e, na centralidade que ocupa, alimenta todas." (SCHÜLER, 1897, 145). E: “Augusto Meyer move-se no centro do modernismo sul-rio-grandense. Recebe a proclamação do grupo de São Paulo como possibilidade entre outras." (SCHÜLER, 1897, p. 204); Flávio Loureiro Chaves (1980, apud CARVALHAL, 1987, p. 35) sintetiza os grandes temas de Augusto Meyer:

Os temas que o acompanharam permanecem invariavelmente os mesmos porque fixam as linhas mestras de seu universo psicológico: a recuperação do passado, a volta à natureza, o privilégio da fantasia infantil sobre a racionalidade. No mito da infância perdida, que sempre retorna como preocupação itinerante e obsessiva, se estrutura uma obra poética que tem origem na velha tradição romântica e atinge o paradoxo contemporâneo do indivíduo que indaga sobre a própria identidade. Na família intelectual de Machado, de Proust, de Kafka, de Borges, de Fernando Pessoa, Augusto Meyer é um homem do nosso tempo.

E Guilhermino Cesar (1980, apud CARVALHAL, 1987, p. 36) credita relevância para o poeta, afirmando enfaticamente: "Qualquer que seja, no futuro, a sua fortuna crítica, Augusto Meyer jamais deixará de ser lembrado em nossa literatura."

Ao lado das considerações de alguns dos mais importantes críticos gaúchos, pode-se, a partir da poesia de Augusto Meyer, configurar um perfil poético, que auxilia o leitor na compreensão das 
profundas construções poéticas de seu autor. A constituição de um perfil poético implica necessariamente a leitura e compreensão de um conjunto satisfatório de poemas do autor em questão. No caso de Meyer, tomam-se como corpus as poesias compiladas pelo autor e publicadas em Poesias - 1922-1955, de 1957.

Pode-se organizar o perfil poético de Augusto Meyer da seguinte maneira: $1^{\circ}$ ) apesar de inovador, Meyer encontra-se divido entre Simbolismo e Modernismo; $2^{\circ}$ ) renova o Regionalismo gaúcho pelo Modernismo, conforme salienta Bertussi (2009, p. 88):

Foi aguda a percepção da crítica de que o poeta pôde renovar o Regionalismo. Moysés Vellinho demonstrou como a tendência precisa alçar-se do 'pitoresco', já esgotado, para uma dimensão humana, que Augusto Meyer alcançou, passando pelo processo representado pela visão alegre e pueril de um primeiro momento, em Coração verde, para chegar à tradução de inquietações existenciais maiores, em Giraluz, sem nunca perder de vista o regional.

$3^{\circ}$ ) reforça o subjetivismo simbolista, pois através do individual busca-se o universal, tornado-se visível a subjetividade do poeta e Bilu, o anti-herói, fato que substitui o tipo gauchesco mitificado; $4^{\circ}$ ) considera a técnica como importante para a criação poética, juntamente com a inspiração; 5º de acordo com Schüler (1987, p. 145) a poesia de Meyer pode ser vista como uma poesia ontológica (ontologia: Gr. ontos e logoi, "conhecimento do ser"): "Por notarmos nele a constante tendência de explorar os fundamentos do que é, 
designamos de ontológica a sua poesia."Aqui, faz-se necessária uma observação fundamental: o eu não chega a se definir em Meyer, como fica claro no poema em prosa "Magali": "Se eu fosse pintor, pintava os teus olhos, porque eles me vêem como eu não sou. Mas eu não sou, sou uma vontade de ser. Só os teus olhos são fiéis. Só o silêncio não mente." (MEYER, 1957, p. 197). Decorrente disso é o fato de: a) o eu divide-se no todo, à semelhança de Fernando Pessoa e seu processo de despersonalização, processo criador dos heterônimos, fato que relativiza a verdade, pois ela é vista sob diferentes perspectivas, como fica claro em "Galeria dos espelhos": "Teto, paredes, chão, tudo, espelho. Minha imagem multiplicou-se tanto que perdi a conta. Era eu, mais eu, mais mil eus e atrás deles, mais outros mil. Fiquei espavorido com a idéia de ter de suportar a companhia suspeita de tantos eus, quando um só, francamente já me enche." (MEYER, 1957, p. 200). b) pelo fato do mundo repousar no eu e o eu se confundir com o todo, Meyer não experimentará realmente o outro. Isso não constitui um tranquilo ponto de chegada, é a síntese de toda uma inquietação. c) o auto-retrato é sempre impossível. Não se pode concluí-lo, porque não se conhece o modelo: “Onde está o original? Não sei." (MEYER, 1957, p. 201) Esse "não sei" é "eco de toda a lírica moderna e revela o homem ocidental minado pela dúvida." (SCHÜLER, 1987, p. 197). O poema "Sanga Funda" é um ótimo exemplo, pois atesta o pertencimento de Meyer ao Simbolismo e revela o mergulho intimista na subjetividade do poeta. Veja-se: 
Vem ver esta sanga funda com rermansos de água clara: lá embaixo o céu se aprofunda, a nuvem passa e não pára.

Numa cisma vagabunda, olhando-me cara a cara, quantas vêzes me abismara: água clara... alma profunda...

E que estranho era o meu rosto no momento em que o sol-pôsto punha uns longes na paisagem!

Aprendi a ser bem cedo segrêdo de algum segrêdo, imagem, sombra da imagem... (MEYER, 1957, p. 14)

Importa fazer algumas considerações sobre o poema transcrito. $O$ primeiro verso do primeiro terceto exprime a impossibilidade do auto-retrato. Já, o último verso do segundo terceto e também do poema, demonstra que o poeta busca por um eu "estranho", que não se constitui em imagem e identidade, pois não pode oferecer mais do que "imagem, sombra de imagem...". Outro exemplo é "Espelho": "Quem é êsse que mergulhou no lago liso do espelho / e me encara de frente à claridade crua? [...]" (MEYER, 1957, p. 69$) ; 6^{\circ}$ ) o poeta valoriza o cotidiano, a infância; $7^{\circ}$ ) apresenta forte telurismo, isto é, amor à terra, à querência; $8^{\circ}$ ) dá nova nuance para a 
dicotomia campo cidade; $9^{\circ}$ ) apresenta uma contínua indagação pela condição humana; $10^{\circ}$ ) vale-se da liberdade formal dos modernistas, ainda que de forma ponderada; $11^{\circ}$ ) Schüler (1987, p. 199) anota a grande ruptura temática da obra de Augusto Meyer: abrir "fendas nas certezas seculares.” A construção desse perfil poético poderia incorporar outros aspectos, todavia julgamos ser os aqui examinados dignos de dar uma boa visão da poesia de Meyer.

\section{A presença da tradição na poesia de Augusto Meyer}

A literatura oral e a literatura regionalista romântica gaúcha também imprimiram em suas produções características que nos ajudam a configurar a tradição na poesia regionalista sul-riograndense, das quais se pode citar: (a) o mito do gaúcho: "monarca das coxilhas" e "centauro dos pampas"; (b) apologia ao espaço idealizado; (c) a mulher idealizada; (d) linguagem monárquica; (e) dicotomia campo/cidade $[$ campo $=$ paraíso], $[$ cidade $=$ degradação $]$; (f) telurismo; (g) otimismo; (h) hospitalidade. A par desses traços, Augusto Meyer construirá a ponte entre tradição e modernidade, dando nova nuance para tais características. Veja-se, como primeiro exemplo, "Sesteada":

Lindo recanto! O biri amarelo ou encarnado, cresce à margem do banhado com touças de sarandi 
Um maricá, retratado nas águas, um bem-te-vi, tudo é sombra e aceno aqui para o viajante cansado.

Procuremos um lugar onde eu possa descansar chegando ao povo bem cedo:

E, nos pelegos deitado, ver o móbil rendilhado que o sol tece no arvoredo.

(MEYER, 1957, p. 10)

A própria disposição do poema já fornece indícios de sua filiação à tradição: é um soneto, os versos são heptassílabos, regulares e rimados, como preconizava a poesia romântica gauchesca. Além disso, o uso do soneto leva em conta as influências dos parnasianos e simbolistas. O título do poema já indica um hábito tradicional dos gaúchos: o ato de dormir a sesta, conforme se pode notar pelos dois tercetos. Somado a esse hábito, está a descrição de um espaço alegorizado, idealizado, conforme a tradição romântica, construindose uma cena bucólica para o olhar humano, como se nota pela presença do biri, do sarandi, do maricá, do bem-te-vi. O "lindo recanto" aludido pelo poeta é o campo, que dá lugar a esse ambiente cheio de paz, onde "tudo é sombra e aceno". 
"Ó de casa" dá continuidade a essa relação do homem do campo com o seu universo, reapresentando elementos caros à tradição:

Ó de casa! vou bradando desde a cancela fronteira e um guaipeca na porteira responde logo ladrando.

Morocha conversadeira me aparece e vai saudando minha vinda e convidando para o mate, hospitaleira.

Desmonto. De vez em quando o cachorrinho ainda late ao meu baio, que retouça.

E eu negaceio, gozando o gosto amargo do mate e os doces olhos da moça.

(MEYER, 1957, p. 13)

Os elementos cultivados pela tradição oral e romântica são reintroduzidos pelo poeta, tais como: (a) a hospitalidade do gaúcho, temática do poema, verificada no próprio título e na segunda estrofe, assim como o "guaipeca", o "cachorrinho" que recebe o poeta "ladrando" também evidencia a hospitalidade, pois seus latidos não são de defesa, são de acolhimento; (b) a figura do cavalo, componente fundamental da vida do gaúcho, também se faz presente, através das 
sentenças "Desmonto." e "ao meu baio que retouça." (c) a "morocha", espanholismo que significa morena introduz a mulher, com os seus "doces olhos de moça”, "conversadeira”, que saúda o visitante com a bebida tradicional do gaúcho: o mate, que, graças aos “doces olhos da moça", tem o seu "gosto amargo" amenizado; (d) do ponto de vista da linguagem, ocorre o mesmo processo visto em "Sesteada".

O telurismo, traduzido como o amor à terra, à querência, constitui característica basilar da tradição, sendo utilizado por Meyer em poemas como "Raiz nova” e Mãe alegria”, por exemplo. Do primeiro, são representativos os fragmentos: “Toda a minha alma sorve o minuano doido" [...] Ajoelho, agora, e beijo a terra, / e beijo o céu...” (MEYER, 1957, p. 52). Já, do segundo, tem-se como representativo:

Eu sou moço, mãezinha, eu sou tão moço, quero beber o sol na madrugada, as minhas mãos acariciaram profundamente a terra, como um seio moreno que eu conheço e de onde brota o manancial da minha vida.

(MEYER, 1957, p. 58)

Outra característica, a clássica oposição campo/cidade, pode ser descrita da seguinte maneira: "Na realidade, pelo menos desde que existem as cidades, o mundo rural sempre esteve numa relação dialética com o mundo urbano. Isto é, o mundo rural existe numa contraposição com o urbano.” (POZENATO, 2003, p. 93). Tal 
relação dialética, tão em voga na poesia romântica gauchesca, receberá nova configuração pelas mãos de Augusto Meyer. Poemas como "Meia hora" e "Noturno porto-alegrense" corroboram essa reconfiguração operada pelo poeta. Do primeiro, passagens como "A cidade mestiça dorme a sesta de janeiro" (MEYER, 1957, p. 40), que sugere a mistura de hábitos do campo e da cidade, e "E a cidade dorme, / pesada, enorme, / sem ver o orgulho reto e bravo das palmeiras." (MEYER, 1957, p. 40), que simboliza o progresso, o olhar para o alto ainda incipiente, revelam um espaço urbano coabitando naturalmente com o espaço rural, numa espécie de espaço em transição. Do segundo, o excerto abaixo é altamente revelador desse espaço transitório:

Cidade, esparramada na coxilha entre os faróis do canal e o clarão de São João, meu amor é uma gaita querendo a querência, teu noturno é um dorido dem-dom de violão.

(MEYER, 1957, p. 188)

Fica claro pela estrofe transcrita a mescla de valores do universo campeiro com as inovações da cidade, situação ressaltada por Pozenato (2003, p. 93): "Não são dois universos que se desenvolvem em separado, cada um com a sua dinâmica própria. Pelo contrário, tanto a dinâmica urbana quanto a dinâmica rural são influenciadas por um mesmo processo." Portanto, o que Meyer revela é uma interação entre o campo e a cidade, destoando dos moldes tradicionais, ainda que sugeridos por eles. 


\section{A presença da modernidade na poesia de Augusto Meyer}

Ao renovar a tendência regionalista gaúcha via Modernismo, Augusto Meyer o faz através da inserção de novos temas: a região como pretexto para o mergulho no eu e a busca filosófica; a instituição de anti-heróis; e o reaproveitamento do popular, levando em conta as propostas nacionalistas do movimento modernista, mas que já nos vêm do Romantismo. Destacaremos também a nova linguagem utilizada por Meyer, a fim de demonstrar as inovações em relação à moldes tradicionais, fato que gera uma nova forma de apreender o mundo, ainda que de alguma forma vinculada à tradição. Em relação ao primeiro tema, o poema "Sanga funda" é um ótimo exemplo, visto que a projeção da divisão do eu utiliza-se da paisagem, a sanga; contudo, esta funciona como mero pretexto para as revelações subjetivas do poeta. "Oração ao Negrinho do Pastoreio" também revela essa perspectiva. Valendo-se de uma das mais populares lendas do folclore sul-rio-grandense, "o poeta articula o drama do Negrinho ao conflito individual." (CARVALHAL, 1987, p. 11). Segundo a lenda, se a pessoa acender uma vela para o Negrinho ele atenderá ao pedido de encontrar aquilo que o indivíduo perdeu, como fica evidente em

Negrinho do Pastoreio, venho acender a velinha que palpita em teu louvor. 
Negrinho do Pastoreio,

diz que você acha tudo se a gente acender um lume de velinha em teu louvor. (MEYER, 1957, p. 125)

$\mathrm{Na}$ medida em que narra a lenda do Negrinho (eis a região servindo como pretexto), o poeta faz a sua súplica:

Eu quero achar-me, Negrinho! (Diz que você acha tudo) Ando tão longe, perdido... Eu quero achar-me, Negrinho: a luz da vela me mostre o caminho do meu amor. (MEYER, 1957, p. 126)

Esse pedido revela a busca filosófica pelo eu, pela própria identidade, pelo significado de sua existência, podendo suas raízes ser encontradas no movimento filosófico e literário conhecido como Existencialismo, efetivando-se em filósofos como Arthur Schopenhauer, Søren Kierkegaard, Friedrich Nietzsche, Edmund Husserl, Martin Heidegger, Jean-Paul Sartre, Simone de Beauvoir, Maurice Merleau-Ponty, e nos escritores Fiódor Dostoiévski, Albert Camus, Boris Vian e o próprio Sarte. ${ }^{6}$ Contudo, o próprio poeta acaba por se conformar com a impossibilidade de achar-se:

${ }^{6}$ Importa considerar que Camus e Heidegger rejeitaram com veemência o rótulo de existencialistas. 
Ah os caminhos da vida ninguém sabe onde é que estão!

Negrinho santo, Negrinho, quero aprender a não ser! Quero ser como a semente na falação de Jesus, semente que só vivia e dava fruto enterrada, apodrecendo no chão.

Assim, o "aprender a não ser" é o destino do poeta, uma escolha que ele faz intencionalmente. A conhecida ideia de Sartre, "A existência precede a essência" ${ }^{7}$, poderia ser muito bem aplicada a esse caso, pois o poeta quer existir, ser, antes de se dar conta de que ninguém sabe onde estão os caminhos da vida. Tal empreitada, somada às proposições do Existencialismo, encontra respaldo nas palavras de Crowell (2010): “A contribuição fundamental do pensamento existencial reside na ideia de que a identidade é

\footnotetext{
${ }^{7}$ Vale lembrar que essa expressão de Sartre deriva de uma sentença de Heidegger (Ser e tempo): "Das 'Wesen' des Daseins liegt in seiner Existenz", que pode ser traduzida por "A 'essência' do Dasein reside na sua existência”. Apesar de Heidegger afirmar que Sartre entendeu de forma inadequada o sentido da sentença, pode-se ver aí uma raiz do que Sartre desenvolve em termos de seu pensamento existencialista.
} 
constituída nem pela natureza, nem pela cultura, uma vez que 'existir' é precisamente constituir tal identidade." ${ }^{8}$ A culminância desse processo se dá com a ideia que perpassa os cinco últimos versos do poema: "O poeta espera ser reabsorvido pela terra fecunda. A vida retorna ao seu lugar de origem e o ciclo vital se repete indefinidamente." (SCHÜLER, 1987, p. 202).

Somada à busca filosófica pela existência está a criação de um anti-herói, o "Bilu". Esse duplo movimento implica uma séria consequência para a tradição: a ausência do gaúcho mitificado, que cede lugar para a subjetividade do poeta e a luta sem trégua de Bilu pela sobrevivência em um mundo urbanizado. Não há mais espaço para homens donos de si, montados em seus cavalos, como legítimos "centauros dos pampas" e "monarcas das coxilhas". Todavia, Bilu "possui um lado telúrico, que talvez possa, em parte, salvá-lo do vazio, pois tem amor à querência e 'aspira a força da terra"'. (BERTUSSI, 2009, p. 98).

Em "Bilu" fica clara essa luta do anti-herói, que nada mais é do que um elemento da engrenagem da vida:

Tu também estás prêso na engrenagem, Bilu, tua cabeça trabalha como um jogo de roldanas.

Vai tocando: o teu destino foi gravado na areia.

\footnotetext{
${ }^{8}$ No original: "The fundamental contribution of existential thought lies in the idea that one's identity is constituted neither by nature nor by culture, since to "exist" is precisely to constitute such an identity."
} 
Tudo é poema, criança. Você não sabe nada, felizmente: saber é saber que não se sabe.

(MEYER, 1957, p. 134)

O reforço à desconstrução do mito do gaúcho, do qual Bilu é exemplo, faz-se presente em "Bailada":

Ai Bilu de corincho caído, Ai Bilu de corincho quebrado, Quem te viu tão desenxabido, Quem te vê tão desenganado. (MEYER, 1957, p. 158)

Poderíamos retratar o gaúcho tradicional segundo as qualidades acima transcritas? Não, de forma alguma. Além disso, "caído", "quebrado", “desenxabido" e "desenganado" podem configurar aquilo que os modernistas chamariam de "belo feio" ou "grotesco". Assim, Bilu é o oposto da versão clássica do homem gaúcho, apesar de revelar amor pela terra, como fica visível no seguinte verso de "Chewing gum": "aspira [ele] a fôrça da terra possante e contente." (MEYER, 1957, p. 138). Os adjetivos "possante" e "contente" revelam uma faceta de Bilu que destoa dos tradicionais anti-heróis "Tatu” e Antônio Chimango: enquanto estes são frutos de uma construção sociológica, aquele é resultado de uma inquirição filosófica do próprio poeta, de modo que a sua miserabilidade não decorre do plano social, mas do humano-existencial, como fica evidente neste trecho de "Chewing gum": "Depois: / indicativo 
presente / caio em mim." (MEYER, 1957, p. 138), situação que reforça a subjetividade do poeta, pois em Bilu está velada a figura do próprio poeta.

Oswald de Andrade e Mário de Andrade, dois dos principais mentores do movimento modernista brasileiro, defendiam em suas respectivas plataformas de reforma literária o reaproveitamento do popular, isto é, uma volta às nossas origens, onde deveria ser empregada a verdadeira língua nacional, de onde é sintomática a célebre sentença do Manifesto Antropófago, escrito por Oswald de Andrade: "Tupy or not tupy, that is the question". De forma alguma indiferente a essas ideias, Augusto Meyer as incorpora em sua produção poética, como atestam os poemas "Gaita", "Puladinho" e "Balada de Bilu". No primeiro, onde se faz presente a palavra "vida", figuraria "mulher", levando em conta a cantiga "Prenda minha", do cancioneiro popular, fato que identifica o diálogo intertextual com a cantiga popular. ${ }^{9}$ No segundo, temos a presença do mitológico SaciPererê: "Salta o Saci como um diabinho, / vira e gira, remexendo o puladinho." (MEYER, 1957, p. 135). O terceiro, por sua vez, estabelece vínculo com um elemento caro à tradição gaúcha: o contador de histórias. ${ }^{10}$ Veja-se:

\footnotetext{
9 "Eu não tinha mais palavras, / vida minha, / palavras de bem-querer; / eu tinha um campo de mágoas, / vida minha, para colhêr.” (MEYER, 1957, p. 50).

${ }^{10}$ Basta pensar em Blau, o célebre contador dos causos que integram os Contos gauchescos, de João Simões Lopes Neto.
} 
Bilu, compadre, conte uma história, que foi, meu bem, que você viu?

"Vi Lenine dançando shimmy, vi Mlle. Moral, chanteuse, vi a estátua da Liberdade na corda bamba do bate-bôca, vi minha infância brincar de roda e a fonte cantar a eterna canção." (MEYER, 1957, p. 143)

Percebe-se que essa parceria de Bilu com o contador de histórias está imbuída de uma mescla entre uma cultura que mistura o popular e o erudito, como a infância do poeta com figuras históricas como Lenine e a estátua da Liberdade. São situações que aproximam o popular do erudito de forma que ambos saem reconfigurados, expressando novas possibilidades interpretativas.

Ao lado dessas características, está também uma nova forma de uso da linguagem, compatível com as propostas modernistas de então. A nova sintaxe utilizada pelo poeta permite dar forma à deformação e consequente fragmentação metonímica do universo, como se verifica em "Ressolana":

O mormaço é a fumaça da macega.

Treme o longe diluído na quentura. O boi desce a recosta em busca da sombra, mas pára logo, abombado. Lá no alto, voando, bebendo o azul, subindo sempre - urubu... 
Feliz...

O calor queima a terra, ferve o ar.

(Memória de marulhos, gôsto de espuma limo areia branca.)

A cabeça do alazão é uma chama esbelta cortando o campo a trote largo. Vejo as orelhas agudas que se movem, sinto o corpo fremente do cavalo.

Há tanta harmonia entre o choque dos cascos e o meu tronco agitado na vibração febril, que eu compreendo a glória animal da carreita-

Vou!

enrolando na fôrça do sol. (MEYER, 1957, p. 70)

O poema apresenta dois planos temporais (presente $\mathrm{e}$ passado) que acabam se sobrepondo: ao lado do presente, está a "(Memória de marulhos, / gôsto de espuma limo areia branca.)", que remete ao passado de outrora. Além disso, o plano externo e o interno também se misturam: o externo, plano visual, da paisagem entra em simbiose com o interno, que representa o sentimento de felicidade do poeta, expresso pela frase elíptica "Feliz...", seguida de reticências. A própria disposição dos enunciados em frases soltas permite que se crie uma nova lógica para a captação do real: palavras 
como "mormaço", "longe", "boi", "urubu" formam esse espaço metonímico, que se vale ainda da "cabeça do alazão", referência ao cavalo e ao "meu tronco agitado na vibração febril" alude ao cavaleiro. A reunião desses elementos cria uma nova forma de ver o espaço gaúcho, diferente daquela que se edifica na tradição.

\section{Considerações finais}

Ao elegermos a poesia de Augusto Meyer como corpus para a análise empreendida, surgiu uma questão fundamental: como configurar teoricamente os conceitos de tradição e modernidade? Com o objetivo de encontrar possíveis respostas para essa questão, buscamos autores que discutem tais conceitos, respeitando a matriz teórica de cada um. O conceito de tradição em Gadamer é diferente daquele de Eliot. Enquanto o primeiro localiza-se na esfera filosófica, o segundo localiza-se no campo literário. Sabemos que o diálogo entre essas duas áreas do conhecimento é possível, lembrando da estruturação das teses de Hans Robert Jauss, que devem grande parte de sua constituição à hermenêutica gadameriana. Portanto, uma articulação é possível, desde que se respeite o contexto de cada teórico. Já, na esfera dos autores que discutem a modernidade, verifica-se uma maior interdependência entre eles, visto que tanto Benjamin (2002) quanto Berman (1986) creditam papel relevante para Baudeleire no que toca à definição do espírito moderno. 
Assim, a compreensão dos conceitos de tradição e modernidade através dos autores referidos mostrou-se útil para a apreciação crítica da produção poética gauchesca de Augusto Meyer. Tal produção poética pode ser estudada por vários vieses, entre os quais escolhemos a relação entre tradição e modernidade, pelo fato de ser uma temática cara à literatura gaúcha. Se em $O$ vaqueano, de Apolinário Porto Alegre, apresenta-se uma visão idealizada do gaúcho, a mesma não estará em A prole do corvo, de Luiz Antonio de Assis Brasil, obra fortemente marcada por uma atitude de releitura da história sul-rio-grandense, especialmente do período entre os anos 1835-1845. Esse não é um exemplo meramente ilustrativo, pois, na medida em que lermos uma obra que retoma a tradição, para resgatála ou superá-la em renovação, estaremos refazendo o percurso efetuado por Augusto Meyer. De qualquer forma, Meyer realiza uma releitura transformadora, pois, ao estabelecer relações entre tradição e modernidade, na poesia regionalista gauchesca está trazendo aspectos da tradição que não foram esquecidos na modernidade, ora por estarem enraizados na cultura, ora por revelaram a própria identidade dos indivíduos que compõem essa cultura, no caso, a cultura sul-rio-grandense ao mesmo tempo em que opera mudanças renovadoras modernistas. 


\section{Referências}

BAUDELAIRE, Charles. Sobre a modernidade. Rio de Janeiro: Paz e Terra, 1996.

BENJAMIN, Walter. A modernidade e os modernos. Rio de Janeiro: Tempo Brasileiro, 1975.

. "Paris, capital do século XIX”. In: LIMA, Luiz Costa. Teoria da literatura em suas fontes. 3. ed. Rio de Janeiro: Civilização Brasileira, 2002. v. 2.

BERMAN, Marshall. Tudo que é sólido desmancha no ar: a aventura da modernidade. São Paulo: Companhia das Letras, 1986.

BERTUSSI, Lisana Teresinha. Tradição, modernidade, regionalidade: poesia regionalista gauchesca de 1922 a 1932. Porto Alegre: Movimento; Caxias do Sul: Educs, 2009.

CARVAlHAL, Tania Franco. Augusto Meyer: poesia, prosa e ensaio. Porto Alegre: IEL, 1987.

CROWELL, Steven. "Existentialism". ZALTA, Edward N., The Stanford Encyclopedia of Philosophy (Winter, 2010 Edition).

Disponível em http://plato.stanford.edu/archives/win2010/entries/existenti alism/, acesso em 21/08/2013.

ELIOT, T. S. Critical essays. London: Faber \& Faber, 1932. 
FISCHER, Luís Augusto. Literatura gaúcha. Porto Alegre: Leitura XXI, 2004.

GADAMER, Hans-Georg. Verdade e método I: Traços fundamentais de uma hermenêutica filosófica. Petrópolis: Vozes, 2008.

LAWN, Chris. Compreender Gadamer. 3. ed. Petrópolis: Vozes, 2011.

MEYER, Augusto. Poesias: 1922-1955. Rio de Janeiro: Livraria São José Editora, 1957.

POZENATO, José Clemente. Processos culturais: reflexões sobre a dinâmica cultural. Caxias do Sul: Educs, 2003.

SCHÜLER, Donaldo. A poesia no Rio Grande do Sul. Porto Alegre: Mercado Aberto, 1987.

VELLINHO, Moysés. Letras da província. 2. ed. Rio de Janeiro: Globo, 1960.

ZILBERMAN, Regina. A literatura no Rio Grande do Sul. 2. ed. Porto Alegre: Mercado Aberto, 1982. 